\title{
Predicting Factors of Chronic Subdural Hematoma Following Surgical Clipping in Unruptured and Ruptured Intracranial Aneurysm
}

\author{
Min-Yong Kwon, M.D., Chang-Hyun Kim, M.D., Chang-Young Lee, M.D. \\ Department of Neurosurgery, Dongsan Medical Center, Keimyung University School of Medicine, Daegu, Korea
}

\begin{abstract}
Objective : The aim of this study is to analyze the differences in the incidence, predicting factors, and clinical course of chronic subdural hematoma (CSDH) following surgical clipping between unruptured (UIA) and ruptured intracranial aneurysm (RIA).

Methods : We conducted a retrospective analysis of 752 patients (UIA : 368 and RIA : 384) who underwent surgical clipping during 8 years. The incidence and predicting factors of CSDH development in the UIA and RIA were compared according to medical records and radiological data.

Results : The incidence of postoperative CSDH was higher in the UIA (10.9\%) than in the RIA (3.1\%) $(p=0.000)$. In multivariate analysis, a high Hounsfield (HF) unit (blood clots) for subdural fluid collection (SFC), persistence of SFC $\geq 5 \mathrm{~mm}$ and male sex in the UIA and A high HF unit for SFC and $\mathrm{SFC} \geq 5 \mathrm{~mm}$ without progression to hydrocephalus in the RIA were identified as the independent predicting factors for CSDH development $(p<0.05)$. Conclusion : There were differences in the incidence and predicting factors for CSDH following surgical clipping between UIA and RIA. Blood clots in the subdural space and persistence of SFC $\geq 5 \mathrm{~mm}$ were predicting factors in both UIA and RIA. However, progression to hydrocephalus may have in part contributed to low CSDH development in the RIA. We suggest that cleaning of blood clots in the subdural space and efforts to minimize $\mathrm{SFC} \geq 5 \mathrm{~mm}$ at the end of surgery is helpful to prevent CSDH following aneurysmal clipping.
\end{abstract}

Key Words : Chronic subdural hematoma $\cdot$ Surgical clipping $\cdot$ Intracranial aneurysm.

\section{INTRODUCTION}

With advances in radiological diagnostic imaging for cerebrovascular disease, detection of unruptured intracranial aneurysm (UIA) is increasing, leading to growth of its preventive clipping surgery. Chronic subdural hematoma (CSDH) as an unexpected complication following surgical clipping of UIA is well known. In these studies, predicting factors such as male sex, advanced age, brain atrophy have been commonly included ${ }^{7,10,14,15)}$.

In our knowledge, there were few literature about CSDH following surgical clipping of ruptured intracranial aneurysm (RIA) because of its low incidence. A study reported that incidence of postoperative CSDH was $2.8 \%$ in UIA and $0.9 \%$ in RIA respectively ${ }^{14)}$. However, The reason that CSDH occurs more frequently in UIA than in RIA has not been studied in detail. Therefore, we investigated the differences in the incidence, predicting factors, and clinical course of CSDH following surgical clipping between UIA and RIA.

\section{MATERIALS AND METHODS}

\section{Patient populations}

A total of 782 intracranial aneurysm clipping surgery was performed in our hospital from January 2005 to December 2012. Among them, 368 and 414 patients of UIA and RIA were treated with surgical clipping respectively. 30 patients with mortality within one month in RIA were excluded in this study. A total of 752 patients were included in this study.

We reviewed medical records containing data on sex, age, smoking, alcohol, the use of anti-thrombotics, hypertension (HTN), diabetes mellitus (DM), and previous cerebrovascular accident (CVA) history. Location of the aneurysm was categorized as the proximal anterior cerebral artery (ACA), distal ACA, middle cerebral artery (MCA), internal carotid artery (ICA), posterior circulation, and multiple aneurysms in separate locations. The proximal ACA classification included A1, anterior communicating artery (AcoA) and proximal A2; and distal

- Received : March 9, 2016 • Revised : March 9, 2016 • Accepted : June 8, 2016

- Address for reprints : Chang-Young Lee, M.D.

Department of Neurosurgery, Dongsan Medical Center, Keimyung University School of Medicine, 56 Dalseong-ro, Jung-gu, Daegu 41931, Korea

Tel : +82-53-250-7730, Fax : +82-53-250-7356, E-mail : nslcy@dsmc.or.kr

- This is an Open Access article distributed under the terms of the Creative Commons Attribution Non-Commercial License (http://creativecommons.org/licenses/by-nc/3.0) which permits unrestricted non-commercial use, distribution, and reproduction in any medium, provided the original work is properly cited. 
ACA included distal A2 and A3.

For the UIA, there were 354 cases (96.2\%), which were incidentally detected on checkup or due to previous stroke, and 14 cases $(3.8 \%)$ which were found due to a neurological deficit related to mass lesion. Surgery proceeded after a pre-operative risk assessment, taking into account patient's age and medical history, and the location, size, and shape of the aneurysm. For the RIA, early emergency surgery was performed in most cases where possible.

Craniotomy was performed through a pterional, interhemispheric, orbitozygomatic, or suboccipital approach, according to the location of the aneurysm. The aneurysm was exposed by excising the arachnoid membrane, and the cerebrospinal fluid (CSF) was partially drained to enable full visualization during the operation and to encourage brain relaxation. In the RIA, CSF was drained through an intraoperative ventriculostomy in some cases to improve cerebral edema and to overcome the CSF circulation defect. Arachnoid plasty for the closure of the excised arachnoid membrane after aneurysm clipping was not performed in both UIA and RIA.

\section{Radiological evaluation}

We reviewed preoperative radiological data containing the degree of brain atrophy in UIA and the Hunt and Hess grade and Fisher scale in RIA. The degree of brain atrophy in UIA was classified by analyzing the axial plane of the preoperative brain CT. Grade 1 was defined as no atrophy with thickness of sulci of cerebral cortex below $1 \mathrm{~mm}$; grade 2 was defined as mild atrophy with thickness above $1 \mathrm{~mm}$ and below $3 \mathrm{~mm}$; grade 3 was defined as definite atrophy with dilated sulci thicker than $3 \mathrm{~mm}$ and a widened Sylvian fissure; and grade 4 was defined as severe atrophy with the features of grade 3 plus an enlarged subdural space (Fig. 1).

The postoperative radiological data was reviewed in detail. CT imaging was performed in all patients immediately after surgery, and the subdural space consisting of pneumocephalus and subdural fluid collection (SFC) below the bone flap was measured by examining the axial plane. For degree of postoperative pneumocephalus, a minimal air-bubble sign was classified as grade 1, air thickness below $10 \mathrm{~mm}$ as grade 2, air thickness above $10 \mathrm{~mm}$ accompanied by compression of the cortex as grade 3 , and huge compression of the cortex signified by the Mount Fuji sign as grade 4 .

We measured the attenuation in Hounsfield (HF) units of SFC below the bone flap, which meant the degree of blood clots in the subdural space. The thickness of SFC was measured as the maximal distance between the inner table of the skull and the cerebral cortex. However, SFC thickness was not determined from immediate postoperative CT, because brain traction during the operation, migration within the cranial cavity caused by gravity, the presence of pneumocephalus would result in an inaccurate measurement. As most of these factors disappeared after a few days in most cases, SFC thickness was measured again at 8 days $\mathrm{CT}$ after surgery.

SFC was classified according to its thickness and progression patterns : In the UIA, SFC below $5 \mathrm{~mm}$ was classified as $\mathrm{I}_{\mathrm{A}}$, and SFC above $5 \mathrm{~mm}$ as $\mathrm{I}_{\mathrm{B}}$. In the RIA, $\mathrm{II}_{\mathrm{A}}$ was defined as SFC below $5 \mathrm{~mm}$ without progression to hydrocephalus, $\mathrm{II}_{\mathrm{B}}$ as $\mathrm{SFC}$ below 5 $\mathrm{mm}$ with progression to hydrocephalus, $\mathrm{II}_{\mathrm{C}}$ as $\mathrm{SFC}$ above 5 $\mathrm{mm}$ without progression to hydrocephalus, $\mathrm{II}_{\mathrm{D}}$ as persisting SFC above $5 \mathrm{~mm}$ and diversion to internal hydrocephalus, and $\mathrm{II}_{\mathrm{E}}$ as persisting $\mathrm{SFC}$ above $5 \mathrm{~mm}$ where surgical treatment was conducted while external hydrocephalus was maintained.

\section{Clinical outcome}

Subsequently, imaging studies were performed regularly throughout the long-term follow-up period. clipping-related CSDH was defined as CSDH following aneurysmal clipping without a history of head trauma. For asymptomatic patients with $\mathrm{CSDH}$, conservative management was performed through serial follow-up examination regardless of hematoma volume. In particular, CT imaging was performed immediately if clinical symptoms developed acutely. For symptomatic patients who developed neurological deficits such as headache, vomiting, or hemiparesis, surgical treatment was performed. Symptoms, previous head trauma history, time interval between aneurysmal clipping and detection of $\mathrm{CSDH}$, side of $\mathrm{CSDH}$, surgical method, presence of recurrence, and pre- and post-operative Glasgow
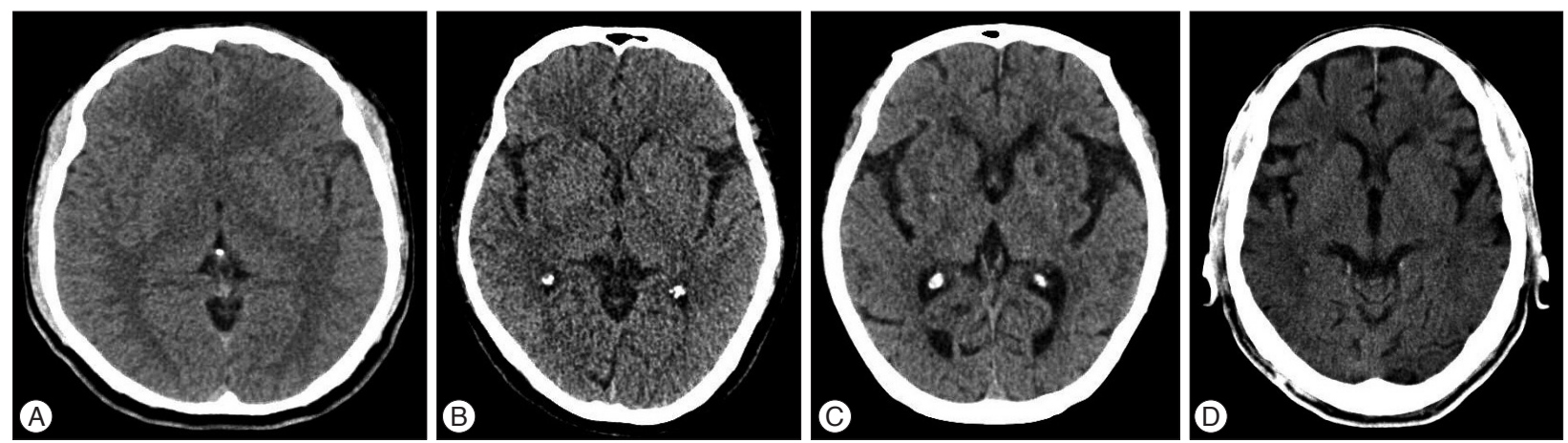

Fig. 1. The degree of brain atrophy. A : Grade 1 is no atrophy with thickness of sulci of cerebral cortex below 1 mm. B : Grade 2 is mild atrophy with thickness above $1 \mathrm{~mm}$ and below $3 \mathrm{~mm}$. C : Grade 3 is definite atrophy with dilated sulci thicker than $3 \mathrm{~mm}$ and a widened Sylvian fissure. D : Grade 4 is severe atrophy with the features of grade 3 plus an enlarged subdural space. 
Coma Scale (GCS) and modified Rankin Score (mRS) were examined for patients who developed CSDH.

\section{Statistical analyses}

SPSS 18.0 for Windows was used for statistical analysis in this study. We described the general characteristics of the patients through descriptive statistics. Chi-square tests were carried out for categorical variables to confirm whether there were any significant predictive factors for CSDH following surgical clipping of intracranial aneurysm. Logistic regression analysis was carried out to elucidate the predictive factors among the variables, and the potential candidates for predictive factors were confirmed through calculation of the odds ratios (ORs) and 95\% confidence intervals via univariate analysis. Significant factors through multivariate analysis were selected to determine independent predictive factors for $\mathrm{CSDH}$ development, and results with $p$-values of less than 0.05 were considered significant.

Table 1. Patient characteristics of all 752 patients who were treated with aneurysmal clipping

\begin{tabular}{lc}
\hline \multicolumn{1}{c}{ Variables } & Value (\%) \\
\hline Sex & $266(35.4)$ \\
Male & $486(64.6)$ \\
Female & $57.73 \pm 11.31$ \\
Age $( \pm$ SD) & \\
Location of aneurysm & $193(25.7)$ \\
Proximal ACA & $26(3.5)$ \\
Distal ACA & $304(40.4)$ \\
MCA & $131(17.4)$ \\
ICA & $11(1.5)$ \\
Posterior circulation & $87(11.6)$ \\
Multiple & \\
Presence of hemorrhage & $368(48.9)$ \\
UIA & $384(51.1)$ \\
RIA & \\
CSDH development & $52(6.9)$ \\
Yes & $700(93.1)$ \\
No & \\
CSDH requiring surgery & $18(2.4)$ \\
Yes & $734(97.6)$ \\
No &
\end{tabular}

ACA : anterior cerebral artery, CSDH : chronic subdural hematoma, ICA : internal carotid artery, MCA : middle cerebral artery, RIA : ruptured intracranial aneurysm, UIA : unruptured intracranial aneurysm

\section{RESULTS}

\section{Incidence of clipping-related CSDH}

Patient characteristics of all 752 patients who were treated with aneurysmal clipping was summarized in Table 1 . The median CT follow-up period was 169.5 days (range 14-3305 days), and the median outpatient department follow-up period was 783.5 days (range 28-3381 days). The total population comprised 266 men and 486 women, and mean age was $57.73 \pm 11.31$ (range 15-88). CSDH developed in 52 patients (6.9\%), of which 18 patients required surgery $(2.4 \%)$.

The UIA group included 368 patients (121 men and 247 women), and mean age was $58.97 \pm 9.55$ (range 16-79). CSDH developed in 40 patients (10.9\%), of which 14 patients required surgery (3.8\%). The RIA group included 384 patients (145 men and 239 women) and mean age was $56.55 \pm 12.67$ (range 15-88). $\mathrm{CSDH}$ developed in 12 patients (3.1\%), of which 4 patients required surgery (1.0\%). The incidence of postoperative $\mathrm{CSDH}$ was higher in the UIA than in the RIA $(p=0.000)$, and the incidence of CSDH requiring surgery was also higher in the UIA than in the RIA ( $p=0.013$ ) (Table 2).

In a total of 52 patients who developed $\mathrm{CSDH}$, it occurred on the ipsilateral side to the craniotomy in 50 patients and on the contralateral side in 2 patients, all of them did not have a history of head trauma. The mean interval between aneurysmal clipping and detection of $\mathrm{CSDH}$ was $62.88 \pm 28.29$ days (range 23197 days). Neurological symptoms such as headache, hemiparesis, confusion, and dysarthria occurred in 18 patients, burr-hole trephination and irrigation surgery was successfully performed in all of whom. The interval between aneurysmal clipping and burr-hole trephination was $66.78 \pm 18.11$ days (range 41-120 days). None of the 18 patients showed impairments of daily living or permanent neurologic deficits caused by complications from or recurrence of CSDH (Table 3).

\section{Predicting factors for development of CSDH}

Variables associated with CSDH following surgical clipping of UIA were listed in Table 4 . We found that significant individual variables for $\mathrm{CSDH}$ development were male sex, age $\geq 60$, high degree of brain atrophy, blood clots in the subdural space (HF unit $\geq 40$ ) and SFC thickness $\geq 5 \mathrm{~mm}$ in the CT immediately after operation, and SFC classification $\mathrm{I}_{\mathrm{B}}$. However, smoking, alcohol, the use of anti-thrombotics, HTN, DM, previous CVA history, location of aneurysm, surgical approach, and postoperative pneumocephalus were found to be unrelated.

Variables associated with CSDH following surgical clipping

Table 2. Incidence of CSDH following surgical clipping in UIA and RIA

\begin{tabular}{|c|c|c|c|c|c|c|}
\hline & \multicolumn{3}{|c|}{ CSDH development (\%) } & \multicolumn{3}{|c|}{ CSDH requiring surgery (\%) } \\
\hline & Yes & No & $p$-value & Yes & No & $p$-value \\
\hline UIA & $40(76.9)$ & $328(46.9)$ & 0.000 & $14(77.8)$ & $354(48.2)$ & 0.013 \\
\hline RIA & $12(23.1)$ & $372(53.1)$ & & $4(22.2)$ & $380(51.8)$ & \\
\hline
\end{tabular}

$\mathrm{CSDH}$ : chronic subdural hematoma, RIA : ruptured intracranial aneurysm, UIA : unruptured intracranial aneurysm 
of RIA were also listed in Table 5. Fisher scale 1-2, blood clots in the subdural space and SFC thickness $\geq 5 \mathrm{~mm}$ in the CT immediately after operation, and SFC classification $\mathrm{II}_{\mathrm{C}}$ were correlated with $\mathrm{CSDH}$ development. Unlike the UIA, there were no associations with sex or age. CSDH development was higher in the Fisher scale 1-2 than in the 3-4, and CSDH did not develop in any patients in whom the Hunt and Hess grade was 4-5.

The potential factors determined by chi-square tests were confirmed to be identical to the significant factors identified by univariate analysis. Factors that satisfied the criterion of $p<0.05$

Table 3. Demographics of patients who developed CSDH requiring surgery

\begin{tabular}{|c|c|c|c|c|c|c|c|c|c|}
\hline No. & Patients & Group & $\begin{array}{l}\text { Location } \\
\text { of aneurysm }\end{array}$ & $\begin{array}{l}\text { Brain } \\
\text { atrophy }\end{array}$ & $\begin{array}{l}\text { HF } \\
\text { unit }\end{array}$ & $\begin{array}{c}\text { SFC } \\
\text { thickness }\end{array}$ & $\begin{array}{c}\text { Classification } \\
\text { of SFC }\end{array}$ & $\begin{array}{l}\text { Clipping-CSDH } \\
\text { interval (day) }\end{array}$ & Symptoms \\
\hline 1 & $\mathrm{M} / 49$ & UIA & Proximal ACA & 2 & 52 & $5 \mathrm{~mm}$ & $\mathrm{I}_{\mathrm{B}}$ & 66 & Hemiparesis \\
\hline 2 & $\mathrm{M} / 51$ & UIA & MCA & 2 & 42 & $7 \mathrm{~mm}$ & $\mathrm{I}_{\mathrm{B}}$ & 41 & Hemiparesis \\
\hline 3 & $\mathrm{M} / 53$ & UIA & MCA & 2 & 69 & $6 \mathrm{~mm}$ & $\mathrm{I}_{\mathrm{B}}$ & 66 & Hemiparesis \\
\hline 4 & $\mathrm{M} / 57$ & UIA & MCA & 2 & 52 & $4 \mathrm{~mm}$ & $\mathrm{I}_{\mathrm{B}}$ & 58 & Headache \\
\hline 5 & $\mathrm{M} / 58$ & UIA & MCA & 2 & 43 & $4 \mathrm{~mm}$ & $\mathrm{I}_{\mathrm{B}}$ & 48 & Headache \\
\hline 6 & $\mathrm{M} / 62$ & UIA & MCA & 3 & 58 & $8 \mathrm{~mm}$ & $\mathrm{I}_{\mathrm{B}}$ & 66 & Headache \\
\hline 7 & $\mathrm{M} / 65$ & UIA & MCA & 2 & 41 & $2 \mathrm{~mm}$ & $\mathrm{I}_{\mathrm{B}}$ & 58 & Hemiparesis \\
\hline 8 & $\mathrm{M} / 72$ & UIA & MCA & 4 & 50 & $7 \mathrm{~mm}$ & $\mathrm{I}_{\mathrm{B}}$ & 80 & Hemiparesis \\
\hline 9 & $\mathrm{M} / 74$ & UIA & MCA & 4 & 47 & $6 \mathrm{~mm}$ & $\mathrm{I}_{\mathrm{B}}$ & 52 & Headache \\
\hline 10 & $\mathrm{~F} / 61$ & UIA & MCA & 2 & 51 & $4 \mathrm{~mm}$ & $\mathrm{I}_{\mathrm{B}}$ & 76 & Hemiparesis \\
\hline 11 & $\mathrm{~F} / 62$ & UIA & MCA & 2 & 52 & $5 \mathrm{~mm}$ & $\mathrm{I}_{\mathrm{B}}$ & 120 & Confusion \\
\hline 12 & $\mathrm{~F} / 66$ & UIA & Proximal ACA & 3 & 52 & $6 \mathrm{~mm}$ & $\mathrm{I}_{\mathrm{B}}$ & 84 & Headache \\
\hline 13 & $\mathrm{~F} / 71$ & UIA & MCA & 3 & 66 & $5 \mathrm{~mm}$ & $\mathrm{I}_{\mathrm{B}}$ & 46 & Headache \\
\hline 14 & $\mathrm{~F} / 72$ & UIA & ICA & 3 & 62 & $6 \mathrm{~mm}$ & $\mathrm{I}_{\mathrm{B}}$ & 70 & Hemiparesis \\
\hline 15 & $\mathrm{M} / 66$ & RIA & MCA & - & 40 & $8 \mathrm{~mm}$ & $\mathrm{II}_{\mathrm{C}}$ & 81 & Dysarthria \\
\hline 16 & $\mathrm{~F} / 58$ & RIA & MCA & - & 57 & $3 \mathrm{~mm}$ & $\mathrm{II}_{\mathrm{C}}$ & 72 & Headache \\
\hline 17 & $\mathrm{~F} / 63$ & RIA & ICA & - & 54 & $4 \mathrm{~mm}$ & $\mathrm{II}_{\mathrm{C}}$ & 60 & Headache \\
\hline 18 & $\mathrm{~F} / 70$ & RIA & ICA & - & 45 & $4 \mathrm{~mm}$ & $\mathrm{II}_{\mathrm{C}}$ & 58 & Headache \\
\hline
\end{tabular}

ACA : anterior cerebral artery, CSDH : chronic subdural hematoma, HF : Hounsfield, ICA : internal carotid artery, MCA : middle cerebral artery, RIA : ruptured intracranial aneurysm, SFC : subdural fluid collection, UIA : unruptured intracranial aneurysm

Table 4. Predicting factors for development of CSDH in 368 patients with UIA

\begin{tabular}{|c|c|c|c|c|}
\hline \multirow{2}{*}{ Variables } & \multicolumn{2}{|c|}{ CSDH development (\%) } & \multirow{2}{*}{ Univariate ( $p$-value) } & \multirow{2}{*}{ Multivariate ( $p$-value) } \\
\hline & Yes & No & & \\
\hline Sex & & & 0.002 & 0.041 \\
\hline Male & $22(55.0)$ & $99(30.2)$ & & \\
\hline Female & $18(45.0)$ & $229(69.8)$ & & \\
\hline Age & & & 0.034 & 0.457 \\
\hline$<60$ & $14(35.0)$ & $174(53.0)$ & & \\
\hline$\geq 60$ & $26(65.0)$ & $154(47.0)$ & & \\
\hline Brain atrophy & & & 0.000 & 0.797 \\
\hline $1-2$ & $23(57.5)$ & $279(85.1)$ & & \\
\hline $3-4$ & $17(42.5)$ & $49(14.9)$ & & \\
\hline Hounsfield unit* & & & 0.000 & 0.000 \\
\hline$<40$ & $0(0.0)$ & $244(74.4)$ & & \\
\hline$\geq 40$ & $40(100.0)$ & $84(25.6)$ & & \\
\hline SFC thickness & & & 0.000 & 0.153 \\
\hline$<5$ & $15(37.5)$ & $222(67.7)$ & & \\
\hline$\geq 5$ & $25(62.5)$ & $106(32.3)$ & & \\
\hline Classification of SFC & & & 0.000 & 0.000 \\
\hline $\mathrm{I}_{\mathrm{A}}$ & $4(10.0)$ & $215(65.5)$ & & \\
\hline $\mathrm{I}_{\mathrm{B}}$ & $36(90.0)$ & $113(34.5)$ & & \\
\hline
\end{tabular}

${ }^{*}$ As a continuous variable measured from the CT image, the Hounsfield unit itself was united in the logistic regression analysis. CSDH : chronic subdural hematoma, SFC : subdural fluid collection, UIA : unruptured intracranial aneurysm, $\mathrm{I}_{\mathrm{A}}$ : $\mathrm{SFC}<5 \mathrm{~mm}, \mathrm{l}_{\mathrm{B}}$ : $\mathrm{SFC} \geq 5 \mathrm{~mm}$ 
Table 5. Predicting factors for development of CSDH in 384 patients with RIA

\begin{tabular}{|c|c|c|c|c|}
\hline \multirow{2}{*}{ Variables } & \multicolumn{2}{|c|}{ CSDH development (\%) } & \multirow{2}{*}{ Univariate ( $p$-value) } & \multirow{2}{*}{ Multivariate ( $p$-value) } \\
\hline & Yes & No & & \\
\hline Sex & & & 0.361 & - \\
\hline Male & $3(25.0)$ & $142(38.2)$ & & \\
\hline Female & $9(75.0)$ & $230(61.8)$ & & \\
\hline Age & & & 0.243 & - \\
\hline$<60$ & $5(41.7)$ & $219(58.9)$ & & \\
\hline$>60$ & $7(58.3)$ & $153(41.1)$ & & \\
\hline Fisher scale & & & 0.019 & 0.942 \\
\hline $1-2$ & $5(41.7)$ & $55(14.8)$ & & \\
\hline $3-4$ & $7(58.3)$ & $317(85.2)$ & & \\
\hline Hounsfield unit ${ }^{*}$ & & & 0.000 & 0.000 \\
\hline$<40$ & $0(0.0)$ & $296(79.6)$ & & \\
\hline$\geq 40$ & $12(100.0)$ & $76(20.4)$ & & \\
\hline SFC thickness & & & 0.025 & 0.151 \\
\hline$<5$ & $7(58.3)$ & $314(84.4)$ & & \\
\hline$\geq 5$ & $5(41.7)$ & $58(15.6)$ & & \\
\hline Classification of SFC & & & 0.000 & 0.001 \\
\hline $\mathrm{II}_{\mathrm{C}}$ & $10(83.3)$ & $59(15.9)$ & & \\
\hline Others & $2(16.7)$ & $313(84.1)$ & & \\
\hline
\end{tabular}

*As a continuous variable measured from the CT image, the Hounsfield unit itself was united in the logistic regression analysis. CSDH : chronic subdural hematoma, SFC : subdural fluid collection, RIA : ruptured intracranial aneurysm, Ilc : SFC $\geq 5 \mathrm{~mm}$ and absence of hydrocephalus

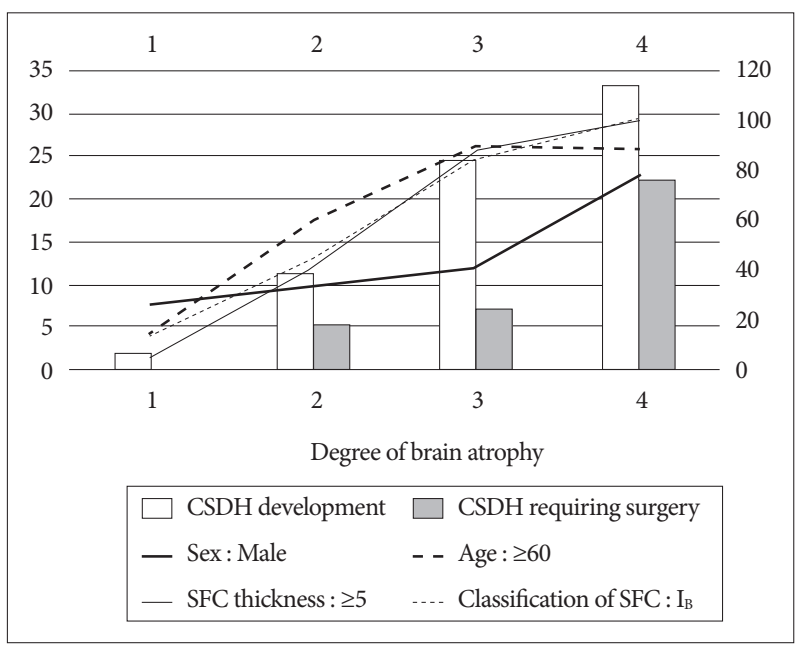

Fig. 2. As the degree of brain atrophy increases, percentages of male sex, age $\geq 60$ years, subdural fluid collection (SFC) $\geq 5 \mathrm{~mm}$, SFC $\mathrm{I}_{\mathrm{B}}$, chronic subdural hematoma (CSDH) development, and $\mathrm{CSDH}$ requiring surgery show a tendency to increase.

were selected for multivariate analysis. These data confirmed that blood clots in the subdural space was an independent factor in both UIA and RIA. SFC $\mathrm{I}_{\mathrm{B}}$ in the UIA and $\mathrm{SFC} \mathrm{II}_{\mathrm{C}}$ in the RIA were also independent factors. On the other hand, although male sex was an independent factor for the UIA, this factor was not a significant factor for the RIA.

\section{Factors affecting clinical outcome of CSDH}

Although brain atrophy was not independently associated with a CSDH development, we think that brain atrophy and postop- erative CSDH would be quite associated. A few factors according to the degree of brain atrophy are listed in Fig. 2. As its degree increased, the percentage of patients with male sex, age $\geq 60$, SFC thickness $\geq 5 \mathrm{~mm}$ in the CT immediately after operation, and $\mathrm{SFC}$ category $\mathrm{I}_{\mathrm{B}}$ generally increased, and the incidence of postoperative CSDH also showed a tendency to increase.

Rates of postoperative CSDH according to the classification of SFC are also different. CSDH following aneurysmal clipping appeared in the order of $\mathrm{I}_{B}, \mathrm{II}_{C}, \mathrm{II}_{\mathrm{D}}$ with differences between groups showing statistical significance. $S F C \mathrm{I}_{\mathrm{B}}$ in UIA that persists SFC thickness $\geq 5 \mathrm{~mm}$ showed the highest percentages of

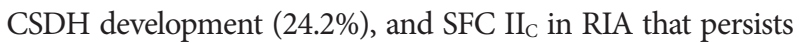
SFC thickness $\geq 5 \mathrm{~mm}$ without progression to hydrocephalus was followed (14.5\%) ( $p=0.010)$. However, despite the significantly prolonged duration of SFC $\mathrm{II}_{\mathrm{D}}(27.47 \pm 218.35$ days $)$ and $\mathrm{II}_{\mathrm{E}}(54.69 \pm 532.39$ days $)$ compared with that of $\mathrm{II}_{\mathrm{C}}(20.49 \pm 25.89$ days), CSDH were occurred in only two cases in the $\mathrm{II}_{\mathrm{D}}$ and $\mathrm{II}_{\mathrm{E}}$ (2.7\%). Those two cases were resolved without requiring surgical treatment. In other words, CSDH occurred less frequently in case of progression to hydrocephalus in the RIA $(p=0.010)$.

\section{DISCUSSION}

\section{Clinical course of CSDH in UIA}

Several recent studies have reported that the incidence of $\mathrm{CSDH}$ following surgical clipping of UIA is in the range of 2.1$5.1 \%^{7,10,14,15,19)}$. Although the incidence in the present study (10.9\%) appeared to be much higher, that was due to inclusion of all CSDH cases which did not require surgery unlike other 
studies. The incidence of CSDH requiring surgery (3.8\%) was nearly consistent with other published reports.

While it has been reported that male sex, advanced age, brain atrophy, location of the aneurysm, and the use of antithrombotic medication are the significant factors of $\mathrm{CSDH}$ following surgical clipping of UIA, there are some differences among the studies $^{7,10,14,15)}$. We also took into account these variables, and the results showed male sex to be an independent predictive factor, whereas the others were not. However, the present study was able to derive at the result of blood clots in the subdural space and SFC classification $\mathrm{I}_{B}$ (persistence of $\mathrm{SFC} \geq 5 \mathrm{~mm}$ ) through detailed review of the characteristics of SFC shown on postoperative CT images.

The first predictor for the development of CSDH following aneurysmal clipping was blood clots in the subdural space, which has not been evaluated in other researches to date. In both UIA and RIA, CSDH did not occur regardless of other factors in patients with attenuation below $40 \mathrm{HF}$ units. A high $\mathrm{HF}$ unit indicates blood clots in the subdural space. It is speculated to be formed from bleeding of excised dura mater, or blood extravasation caused by splitting of the dura-arachnoid interface layer, a weak part of the meninges. Blood clots, well-known as the initial mechanism in CSDH formation, would form a new membrane in the subdural space through the inflammatory and fibrinolytic processes. The external part of the membrane is composed of many capillaries and sinusoids and repeatedly induces micro-hemorrhage, leading to enlargement of the hematoma ${ }^{2,17,20)}$. Therefore, the most important steps to prevent the formation of $\mathrm{CSDH}$ are careful examination by cleaning of blood clots at the end of surgery so that there are no blood clots in the subdural space.

A potential space for SFC also needs to be present for CSDH development. Subdural hygroma is reported to transform into $\mathrm{CSDH}$ in $4-58 \%$ of cases ${ }^{4,9)}$. We could observe the dead space within the subdural space on the postoperative CT, which was filled with hypodense liquid. This seems to be a subdural hygroma caused by excessive non-hematic fluid, which is known to occur commonly after minor head trauma and neurosurgical procedures $^{3,11)}$. Normally the subdural space is not large to occur $\mathrm{CSDH}$, but when the arachnoid membrane is dissected to expose the aneurysm, CSF flows from the subarachnoid space into the subdural space through this passage, causing subdural hygroma.

The most commonly mentioned significant factor for subdural hygroma is brain atrophy ${ }^{4,9)}$. As the patient gets older, resolution of subdural hygroma becomes poorer as re-expansion can be difficult due to severe brain atrophy and increased tissue stiffness. Although brain atrophy was not an independent predictive factor, our results also support this theory. As the degree of brain atrophy increased, the percentage of patients with SFC thickness $\geq 5 \mathrm{~mm}$ in the CT immediately after the operation, SFC category $\mathrm{I}_{\mathrm{B}}$, and occurrence of postoperative CSDH showed a tendency to increase. Several studies including our study also re- port that male sex is an independent factor of CSDH following surgical clipping of $\mathrm{UIA}^{7,10,14,15)}$, and it is speculated that this result is also affected by brain atrophy as shown in Fig. 2. Generally, it is known that brain atrophy is more severe in males than females as they become older, but the cause is not clearly elucidated $^{8,18)}$. Therefore, the surgical treatment necessity of UIA needs to be carefully considered when the patient has severe brain atrophy.

In addition, we should focus on how the opening of the arachnoid membrane affects the occurrence of subdural hygroma after clipping surgery. The incidence of subdural hygroma is known to be higher after clipping surgery than after other neurosurgical procedures, which is thought to be due to more extensive dissection of the arachnoid membrane compared to other procedures ${ }^{13,16)}$. Another study suggested that location of aneurysm is suspected to be an independent factor of postoperative $\mathrm{CSDH}$ since MCA aneurysm needs extensive arachnoid dissection and takes longer the arachnoid healing process of sylvian fissure than that of basal cistern ${ }^{15)}$, but it appeared to be irrelevant in the present study. Therefore, it is crucial to prevent the occurrence of subdural hygroma by aiming for minimally invasive microsurgery through dissecting the membrane only to the degree that is necessary, and by blocking the pathway for subdural hygroma formation through arachnoid repair. There are several recent reports on arachnoid plasty using fibrinogen, thrombin, and suturing of arachnoid membrane as an effort for prevention of CSDH development; however, verification of the effects of these measures is still lacking ${ }^{12,19,21)}$.

\section{Clinical course of CSDH in RIA}

It is known that incidence of CSDH following surgical clipping of RIA is much less common ${ }^{14)}$, and incidence in the RIA was significantly lower than in the UIA in the present study as well. The reason for this is because this has been attributed to brain edema from occupied hematoma, and the low incidence of CSDH development at Fisher scale 3-4 in the present study can also supports this. However, almost studies in RIA were restricted to epidemiological research, detailed analyses of radiological data have not been studied. We hypothesized that the pattern of SFC according to progression to hydrocephalus may be somewhat different, and prevalence of CSDH would also be different in comparison with UIA. Based on this, we were able to determine that $\mathrm{SFC}$ classification $\mathrm{II}_{\mathrm{C}}$ (SFC $\geq 5 \mathrm{~mm}$ without progression to hydrocephalus), along with blood clots in the subdural space were independent predictive factors.

As previously mentioned, SFC in the UIA can be explained by subdural hygroma, whereas SFC in the RIA seems to be different in its nature ${ }^{1,22)}$. Hydrocephalus can occur as blood clots from $\mathrm{SAH}$ blocks the arachnoid granules, triggering an absorption defect in the CSF circulation. Thus, the pressure of subarachnoid space and ventricle containing CSF is abnormally high, and in this condition, considerable amount of CSF is constantly congested in subdural space as if a new tract is formed through the 
dissected arachnoid membrane. Therefore, SFC in the RIA also maintains high pressure and manifests the characteristics of external hydrocephalus, suppressing occurrence of CSDH. Huh et al. ${ }^{6}$ also reported that the subdural pressure is high in SFC accompanied by external hydrocephalus.

According to the osmotic gradient theory in several pathophysiology of the development of $\mathrm{CSDH}^{5)}$, the wall of subdural hematoma is surrounded by semi-permeable membrane, and the inside of hematoma consists of the degradation of blood protein contents. Therefore, there is a discrepancy in osmotic pressure between the inside and outside of hematoma, and the size of hematoma increases gradually. However, in the RIA with high subdural pressure, the incidence of CSDH may be lower as the difference in osmotic pressure is also low. In other words, through this hypothesis, we can explain why CSDH occurs more frequently in UIA than in RIA; and within the same RIA, why it occurs less frequently in the group where it progresses to hydrocephalus $\left(\mathrm{II}_{\mathrm{D}}, \mathrm{II}_{\mathrm{E}}\right)$ compared to the group where it does not $\left(\mathrm{II}_{\mathrm{C}}\right)$.

We analyzed distinctively the characteristics of the SFC and progression to hydrocephalus in postoperative CT images to in- vestigate the clinical course, and determined the significant risk factors that have not been evaluated in other researches to date : blood clots in the subdural space, persistence of SFC $\geq 5 \mathrm{~mm}$, and low subdural pressure. There was a risk of postoperative $\mathrm{CSDH}$ even for the RIA when the above conditions were fulfilled (Fig. 3).

However, because serial follow-up through postoperative CT could not be conducted in all patients of UIA in this study, we faced limitations in analyzing the differences between $\mathrm{CSDH}$ requiring surgery and $\mathrm{CSDH}$ not requiring surgery. Additionally, further studies examining the effectiveness of arachnoid repair and the detailed relations between subdural pressure and incidence of $\mathrm{CSDH}$ are deemed necessary.

\section{CONCLUSION}

The incidence of CSDH following surgical clipping occurred more often in UIA than in RIA. The present study identified the following independent predicting factors for postoperative $\mathrm{CSDH}$ : blood clots in the subdural space, persistence SFC $\geq 5$
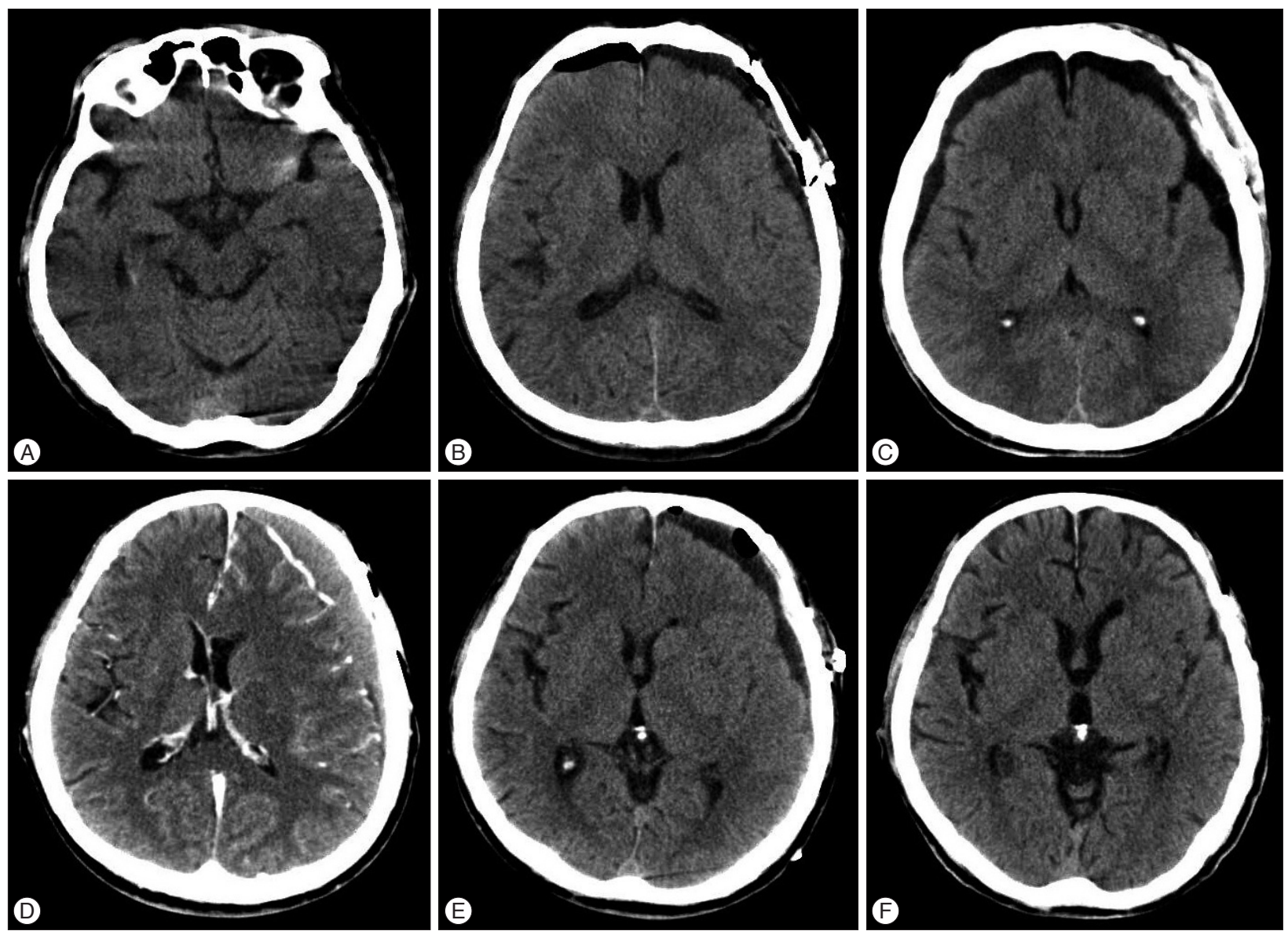

Fig. 3. A : The patient was a 66-year-old man admitted to hospital for ruptured intracranial aneurysm of the left middle cerebral artery bifurcation. Hunt and Hess grade is 3 and Fisher scale is 2. B: The attenuation in Hounsfield units of subdural fluid collection from the CT after the clipping surgery is 40 . SFC thickness is $8 \mathrm{~mm}$. C : CT taken on the 8th day after the operation. SFC thickness is $10 \mathrm{~mm}$ and classification of SFC is Ilc. Hydrocephalus not occurred. The patient was discharged on the 37th day. D : CT taken on the 81st day after the operation when the patient presented with dysarthria. Left chronic subdural hematoma is observed. $\mathrm{E}$ : Burr-hole and irrigation surgery was immediately conducted successfully. F : CT taken on the 325 th day after the operation. No complication or recurrence of CSDH was observed, and the patient's symptoms were completely resolved. 
$\mathrm{mm}$ and male sex in the UIA and blood clots in the subdural space and $\mathrm{SFC} \geq 5 \mathrm{~mm}$ without progression to hydrocephalus in the RIA. Blood clots in the subdural space and persistence of SFC $\geq 5 \mathrm{~mm}$ strongly affected both UIA and RIA. However, progression to hydrocephalus may have in part contributed to low CSDH development in the RIA. We suggest that cleaning of blood clots in the subdural space and efforts to minimize SFC $\geq 5 \mathrm{~mm}$ at the end of surgery is helpful to prevent CSDH following aneurysmal clipping.

\section{References}

1. Alotaibi NM, Witiw CD, Germans MR, Macdonald RL : Spontaneous subdural fluid collection following aneurysmal subarachnoid hemorrhage : subdural hygroma or external hydrocephalus? Neurocrit Care $21: 312-315,2014$

2. Chen JC, Levy ML : Causes, epidemiology, and risk factors of chronic subdural hematoma. Neurosurg Clin N Am 11 : 399-406, 2000

3. Eguchi S, Aihara Y, Hori T, Okada Y : Postoperative extra-axial cerebrospinal fluid collection--its pathophysiology and clinical management. Pediatr Neurosurg 47 : 125-132, 2011

4. Feng JF, Jiang JY, Bao YH, Liang YM, Pan YH : Traumatic subdural effusion evolves into chronic subdural hematoma : two stages of the same inflammatory reaction? Med Hypotheses 70 : 1147-1149, 2008

5. Gjerris F, Sørensen SC : Colloid osmotic and hydrostatic pressures in chronic subdural haematomas. Acta Neurochir (Wien) $54: 53-60,1980$

6. Huh PW, Yoo DS, Cho KS, Park CK, Kang SG, Park YS, et al. : Diagnostic method for differentiating external hydrocephalus from simple subdural hygroma. J Neurosurg 105 : 65-70, 2006

7. Inamasu J, Watabe T, Ganaha T, Yamada Y, Nakae S, Ohmi T, et al. : Clinical characteristics and risk factors of chronic subdural haematoma associated with clipping of unruptured cerebral aneurysms. J Clin Neurosci 20 : 1095-1098, 2013

8. Kanat A, Kayaci S, Yazar U, Kazdal H, Terzi Y : Chronic subdural hematoma in adults : why does it occur more often in males than females? Influence of patient's sexual gender on occurrence. J Neurosurg Sci 54 : 99-103, 2010

9. Kristof RA, Grimm JM, Stoffel-Wagner B : Cerebrospinal fluid leakage into the subdural space : possible influence on the pathogenesis and recurrence frequency of chronic subdural hematoma and subdural hygro- ma. J Neurosurg 108 : 275-280, 2008

10. Lee WJ, Jo KI, Yeon JY, Hong SC, Kim JS : Incidence and risk factors of chronic subdural hematoma after surgical clipping for unruptured anterior circulation aneurysms. J Korean Neurosurg Soc 57 : 271-275, 2015

11. Liu Y, Gong J, Li F, Wang H, Zhu S, Wu C : Traumatic subdural hydroma : clinical characteristics and classification. Injury 40 : 968-972, 2009

12. Mino Y, Hirashima Y, Hamada H, Masuoka T, Yamatani K, Takeda S, et al. : Effect of arachnoid plasty using fibrin glue membrane after clipping of ruptured aneurysm on the occurrence of complications and outcome in the elderly patients. Acta Neurochir (Wien) 148 : 627-631; discussion 631,2006

13. Mori K, Maeda M : Risk factors for the occurrence of chronic subdural haematomas after neurosurgical procedures. Acta Neurochir (Wien) 145 : 533-539; discussion 539-540, 2003

14. Ohno T, Iihara K, Takahashi JC, Nakajima N, Satow T, Hishikawa T, et al. : Incidence and risk factors of chronic subdural hematoma after aneurysmal clipping. World Neurosurg $80: 534-537,2013$

15. Park J, Cho JH, Goh DH, Kang DH, Shin IH, Hamm IS : Postoperative subdural hygroma and chronic subdural hematoma after unruptured aneurysm surgery : age, sex, and aneurysm location as independent risk factors. J Neurosurg $124:$ 310-317, 2016

16. Quintana LM : Chronic subdural hematoma after neurosurgical procedures. World Neurosurg 80 : 482-483, 2013

17. Tanaka Y, Ohno K : Chronic subdural hematoma - an up-to-date concept. J Med Dent Sci 60 : 55-61, 2013

18. Xu J, Kobayashi S, Yamaguchi S, Iijima K, Okada K, Yamashita K : Gender effects on age-related changes in brain structure. AJNR Am J Neuroradiol $21: 112-118,2000$

19. Yagi K, Irie S, Inagaki T, Ishii Y, Saito O, Lee T, et al. : Intraoperative arachnoid plasty has possibility to prevent chronic subdural hematoma after surgery for unruptured cerebral aneurysms. Neurol Med Chir (Tokyo) $55: 493-497,2015$

20. Yamashima $\mathrm{T}$ : The inner membrane of chronic subdural hematomas : pathology and pathophysiology. Neurosurg Clin N Am 11 : 413-424, 2000

21. Yoshimoto T, Houkin K, Ishikawa T, Abe H : Arachnoid membrane closure. Prevention of postoperative cerebrospinal fluid leakage. Surg Neurol 52 : 68-71; discussion 71-72, 1999

22. Yoshimoto Y, Wakai S, Hamano M : External hydrocephalus after aneurysm surgery : paradoxical response to ventricular shunting. J Neurosurg $88: 485-489,1998$ 